OPEN ACCESS

Edited by:

Qingmei XIE,

South China Agricultural

University, China

Reviewed by:

Ahmed Ragab Elbestawy, Damanhour University, Egypt Daniel Oladimeji Oluwayelu,

University of Ibadan, Nigeria

*Correspondence:

Hyun-Jin Shin

shin0089@cnu.ac.kr

Specialty section:

This article was submitted to Veterinary Epidemiology and

Economics,

a section of the journal

Frontiers in Veterinary Science

Received: 02 September 2021 Accepted: 04 November 2021

Published: 01 December 2021

Citation:

Ali MZ, Moula MM, Bhuiyan ZA, Giasuddin M and Shin H-J (2021) First

Isolation and Molecular

Characterization of Chicken Astrovirus and Avian Nephritis Virus in Chickens

in Bangladesh.

Front. Vet. Sci. 8:769489.

doi: 10.3389/fvets.2021.769489

\section{First Isolation and Molecular Characterization of Chicken Astrovirus and Avian Nephritis Virus in Chickens in Bangladesh}

\author{
Md Zulfekar Ali ${ }^{1}$, Mohammad Moktader Moula ${ }^{2}$, Zafar Ahmed Bhuiyan ${ }^{2}$, Md Giasuddin ${ }^{1}$ \\ and Hyun-Jin Shin ${ }^{3,4 *}$
}

${ }^{1}$ Animal Health Research Division, Bangladesh Livestock Research Institute, Dhaka, Bangladesh, ${ }^{2}$ Nourish Central Poultry Laboratory, Nourish Poultry and Hatchery Ltd., Dhaka, Bangladesh, ${ }^{3}$ College of Veterinary Medicine, Chungnam National University, Daejeon, South Korea, ${ }^{4}$ Research Institute of Veterinary Medicine, Chungnam National University, Daejeon, South Korea

Chicken astrovirus (CAstV) and avian nephritis virus (ANV) are enteric viruses of poultry and have infected a wide range of poultry species worldwide, causing runting-stunting syndrome (RSS), which requires virus screening and results in serious economic damage. No confirmed cases have been reported from Bangladesh. In the present study, CAstV and ANV were monitored in Bangladesh. We monitored samples for CAstV and ANV and compared their genomic sequences to other reference strains. We found $8 / 31$ flocks (25.8\%) were positive for CAstV, 6/31 flocks (19.3\%) had mixed infection of CAstV and ANV, and 1 flock (3.2\%) was positive for ANV. Only ANV and a combination of CAstV and ANV were found in broilers and broiler breeders, but CAstV was found in all types of chickens. We isolated two of each from CAstV and ANV through specific pathogen-free chicken embryonated eggs via the yolk sac route. Phylogenetic analysis based on the ORF1b conserved region of CAstV and ANV suggested that the locally circulating strain was closely related to the strains isolated from India and Brazil. This report is the first molecular characterization of CAstV and ANV in Bangladesh. This study highlights that CAstV and ANV are circulating in Bangladeshi poultry.

Keywords: avian nephritis virus, CAstV, chicken astrovirus, ANV, poultry, Bangladesh

\section{INTRODUCTION}

Good enteric health plays a critical and basic role in successful broiler production by converting feed into meat. Any disturbances in this conversion process, such as mechanical, chemical, or biological hazards, impair nutrient absorption rates, resulting in high economic losses because of poor growth, increased mortality rates, and increased treatment costs (1). The major enteric viruses, including chicken astrovirus (CAstV), avian nephritis virus (ANV), avian rotavirus (AvRV), chicken parvovirus (ChPV), infectious bronchitis virus (IBV), avian reovirus (ARV), and fowl adenovirus (FAdV), are etiologies of enteritis of poultry that are accompanied by high economic losses to the poultry industries (2-5). Enteritis results in the alteration of the gastrointestinal environment and a direct decrease in feed digestion and absorption, consequently elevating the feed conversion ratio (FCR), causing growth retardation 
[commonly known as runting-stunting syndrome (RSS)], and immunosuppression, and an increased flock mortality rate by influencing secondary infections of the gut commensals (6-9).

RSS is relevant to the gastrointestinal health of poultry species and plays a significant role in the chicken meat industry and poultry health management because multiple viruses are involved $(4,10,11)$. RSS is also called malabsorption syndrome, infectious stunting syndrome, helicopter symptoms, uneven growth, and malassimilation (11-17). Avian astrovirus (AAstV) belongs to the family Astroviridae and genus Avastrovirus. To date, six different astroviruses have been identified in avian species based on the species of origin and viral genome characteristics: two turkeyorigin astroviruses [Turkey Astrovirus type 1 (TAstV-1) and type 2 (TAstV-2)]; two chicken-origin astroviruses [Avian Nephritis Virus (ANV) and Chicken Astrovirus (CAstV)]; and two duckorigin astrovirus [Duck Astrovirus type 1 (DAstV-1) and type 2 (DAstV-2)]. ANV has also been detected in turkeys, ducklings, pigeons, and guinea fowl; and TAstrovirus-2-likeviruses have also been found in guinea fowl (18). The genotypic classification, nine avastrovirus genotypes have been reported so far (AAstV-1-9). AAstV-2, -5, -8, -9 (typical chicken ANV) and AAstV-4 (chicken astrovirus, CAstV), are more frequently detected in chickens. There are some uncommonly described astroviruses in chickens such as AAstV-5 (or pigeon ANV-1 detected only in Chinese chickens) and AAstV-1 (TAstV-1 detected only in chickens from Sri Lanka) (19-21).

Morphologically, an astrovirus has a 7-kb-long singlestranded positive-sense RNA and it is nonenveloped, rounded, and 28 to $30 \mathrm{~nm}$ in diameter. Before their molecular characterization, astroviruses were thought to be Picornavirus or enteroviruses because of a typical star-like round morphology and size (22). The avian astrovirus genome contains three overlapping open reading frames, including ORF1a, ORF1b, and ORF2. ORF1a and ORF1b encode the viral protease and polymerase, respectively. ORF2 encodes a VP90 capsid precursor protein that is expressed from a subgenomic RNA (17).

An astrovirus was first detected in a young patient suffering from diarrhea and it has been reported as a causative agent of gastrointestinal disorders in humans and animals (22). Baxendale and Mebatsion (23) reported the isolation and identification of astroviruses from broiler chickens suffering from RSS and recognized them as chicken astroviruses. Currently, CAstV is distributed globally and is emerging in new geographic locations, such as Canada, China, South Korea, India, Italy, Jordan, Australia, and Brazil, in a wide range of avian species, including chickens, guinea, turkeys, fowl, and ducks $(6,22)$. CAstV has historically been associated with hepatitis, enteritis, nephritis, and RSS in turkeys, chickens, some mallard duck species, and wild birds $(16,24)$.

Notably, many researchers have proven that white chick syndrome (WCS) is caused by CAstV (6). WCS is also responsible for decreased egg production and reduction of hatchability by up to $48 \%$ of broiler breeders in the early and late periods of production $(6,21)$. At a young age, infected chicks were observed to have pale-to-white-colored plumage with a brown plumage ring over the neck and head, and the liver was enlarged and had a bronze or greenish color. However, in many cases, both CAstV and ANV were isolated from apparently healthy birds (25-27).

ANV was first reported and isolated from 1-week-old broiler chicks in Japan by Yamaguchi et al. (28). In 2000, it was genetically characterized and classified as an astrovirus under the family Astroviridae by Imada et al. (29). Currently, ANV has been reported in different poultry species in several countries, including India, the United States, Australia, Nigeria, Canada, South America, and Brazil (29-32). ANV has been associated with kidney lesions, growth suppression, and many symptoms, such as enteritis, ruffled feathers, visceral gout, and apathy, and it causes mortality in young chicks $(16,33)$.

Modern diagnostic methodologies have been developed to monitor flocks for CAstV and ANV using isolation and identification, detection using electron microscopy, reverse transcription polymerase chain reaction (RT-PCR), or real-time RT-PCR (rRT-PCR). Indirectly, detection of antibodies is performed using methods such as enzyme-linked immunosorbent assay (ELISA), which is costly and not available in many local markets (6). Many outbreaks of RSS with enteric disorders have also been observed over the years in Bangladesh; however, according to our review of the literature, no reports on either CAstV or ANV viruses have been published.

This study was carried out to survey the infection statutes of CAstV and ANV in different types of poultry farms located in the four districts of Bangladesh with isolation, identification, and molecular characterization of CAstV and ANV. The flocks demonstrated clinical RSS with enteric disorders, and an impact on flock mortality and FCR\% in broiler chickens was demonstrated.

\section{MATERIALS AND METHODS \\ Sample Collection}

The investigation of CAstV and ANV was carried out in five types of chicken flocks [broilers $(n=18)$, broiler breeders $(n=9)$, layer $(n=2)$, layer breeder $(n=1)$, and indigenous (local breed) $(n=1)$ ] from four districts (Gazipur, Rangpur, Mymensingh, and Bogura) of Bangladesh (Figure 1) during 2018 (Table 1). The flock had been diagnosed with enteric problems, such as diarrhea, growth retardation, poor feed conversion ratio, malabsorption syndrome, visceral gout (broiler) and articular gout (broiler breeder, layer, layer breeders and indigenous), culling, and increased mortality. Freshly dead chickens $(n=31)$ from 31 flocks were subjected to postmortem examination, and samples were collected from the kidneys, liver, duodenum, and cecum in phosphate-buffered saline (PBS) supplemented with antibiotics (penicillin: 1,000 units/ml; streptomycin: 1,000 $\mu \mathrm{g} / \mathrm{ml}$ ) and an antifungal agent (amphotericin B $2.5 \mu \mathrm{g} / \mathrm{ml}$ ). The samples were transferred immediately to the laboratory and kept at $-20^{\circ} \mathrm{C}$ until processing.

\section{Sample Preparation}

The tissue samples from each flock were pooled before periodic homogenization in PBS to a final concentration of $10 \%(\mathrm{w} / \mathrm{v})$, and then the supernatant was collected into 1.5-ml Eppendorf tubes by low-speed centrifugation at 4,500 $\times \mathrm{g}$ for $15 \mathrm{~min}$. Finally, 


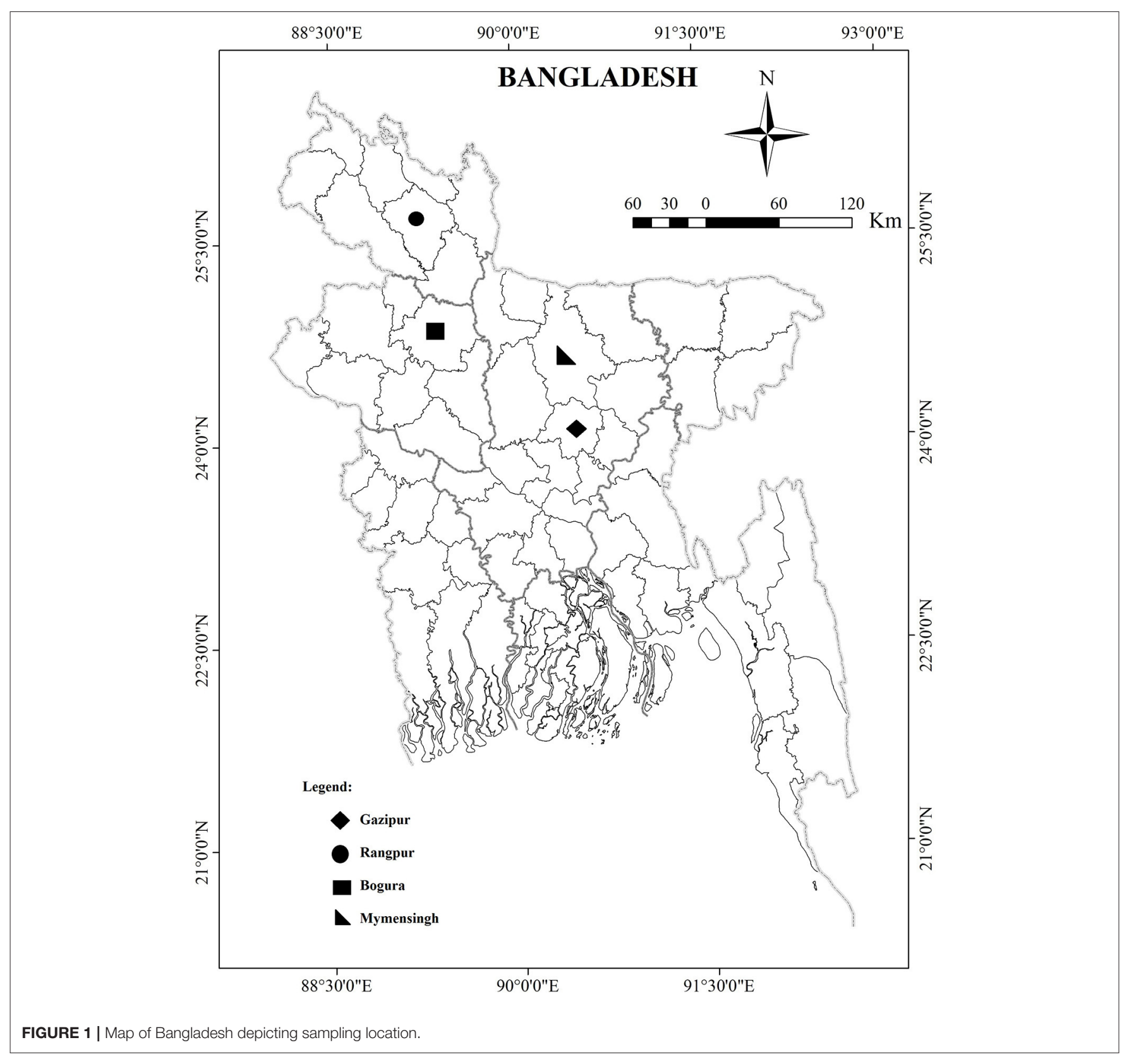

the supernatant was stored at $-80^{\circ} \mathrm{C}$ until RNA extraction. Viral RNA was extracted from $140 \mu \mathrm{l}$ of each supernatant fluid using the QIAamp Viral RNA Mini Kit (Qiagen, Crawley, UK) according to the manufacturer's instructions.

\section{rRT-PCR Assays}

All 31 extracted viral RNA samples were subjected to rRT-PCR assays using primers and a probe reported by Smyth et al. and described in Table 2 (17). The rRT-PCRs were set up in triplicate, and each reaction contained $20 \mu \mathrm{l}$ of reaction mixtures prepared by $10 \mu \mathrm{l}$ of AgPath-IDTM One-step RT-PCR 2x buffer (Applied Biosystems), $0.8 \mathrm{ml}$ of AgPath-IDTM One-step RT-PCR enzyme (Applied Biosystems), a forward and reverse primer
(400 nM), probe $(120 \mathrm{nM})$, and $2 \mu \mathrm{l}$ of RNA template, and nuclease-free distilled water (Applied Biosystems) was added to $20 \mu \mathrm{l}$. A negative control was performed by replacing the RNA template with $2 \mu$ l of nuclease-free distilled water or negative extraction control. Amplification was conducted in an ABI 7,500 fast thermal cycler (Applied Biosystems) with thermal conditions of $45^{\circ} \mathrm{C}$ for $10 \mathrm{~min}$ for the reverse transcription stage and $95^{\circ} \mathrm{C}$ for $10 \mathrm{~min}$ for the initial denaturation stage, followed by 40 cycles of denaturation at $95^{\circ} \mathrm{C}$ for $15 \mathrm{~s}$ and then annealing at $60^{\circ} \mathrm{C}$ for $45 \mathrm{sD}$. All samples were screened for verification of coinfection with Avian reovirus (ARV) according to the primers and protocol of Pantin-Jackwood et al. (34). 
TABLE 1 | Distribution of samples collected from five types of chickens under four areas of Bangladesh (total flock = 31).

\begin{tabular}{|c|c|c|c|c|c|c|c|}
\hline \multirow[t]{2}{*}{ Sl. No. } & \multirow[t]{2}{*}{ Location } & \multicolumn{5}{|c|}{ Type of chick } & \multirow[t]{2}{*}{ Total } \\
\hline & & Broiler & Broiler breeder & Layer & Layer breeder & Indigenous & \\
\hline 1 & Gazipur & 5 & 9 & 1 & 1 & 1 & 17 \\
\hline 2 & Rangpur & 3 & - & - & - & - & 3 \\
\hline 3 & Mymensingh & 3 & - & 1 & - & - & 4 \\
\hline \multirow[t]{2}{*}{4} & Bogura & 7 & - & - & - & - & 7 \\
\hline & Total & 18 & 9 & 2 & 1 & 1 & 31 \\
\hline
\end{tabular}

TABLE 2 | Primer and probe sequences used in rRT-PCR assays for chicken astrovirus and avian nephritis virus.

\begin{tabular}{|c|c|c|c|c|}
\hline Virus & Primer location & Primer sequences & $\begin{array}{c}\text { Product size } \\
\text { (base pairs) }\end{array}$ & Reference \\
\hline \multirow[t]{3}{*}{ Chicken astrovirus } & ORF1b, ORF2 & Forward: 5'-GCTGCTGCTGAAGATATACAG-3' & 70 & Smyth et al. (17) \\
\hline & & Reverse: 5'-CATCССТСТАССAGATITTCTGAAA-3' & & \\
\hline & & Probe: 5'-6FAM CAGAAGTCGGGCCC BHQ1-3' & & \\
\hline \multirow[t]{3}{*}{ Avian nephritis virus } & $3^{\prime}$-Untranslated region & Forward: 5'-GTAAACCACTGGTTGGCTGACT-3' & 56 & \\
\hline & & Reverse: 5'-TACTCGCCGTGGCCTCG-3' & & \\
\hline & & Probe: 5'-6FAM CAGCAACTGACTTC BHQ1-3' & & \\
\hline
\end{tabular}

\section{Virus Isolation}

Two samples were positive for CAstV but negative for ANV, and 2 ANV-positive samples, including one sample that was only ANV positive in the rRT-PCR test, were selected for isolation of CAstV and ANV. The previously processed samples for viral RNA extraction were filtered with a $0.22 \mu \mathrm{M}$ filter and kept for inoculum. Fourteen-day-old specific pathogen-free (SPF) White Leghorn chicken embryonated eggs (CEEs) were used for virus isolation. The filtered inoculum $(0.2 \mathrm{~mL})$ was inoculated into the yolk sac route of SPF CEEs and sealed by melted paraffin. An inoculum of $0.2 \mathrm{~mL}$ of sterile PBS at $\mathrm{pH} 7.4$ was inoculated through the yolk sac route of SPF CEE as a negative control. Next, inoculated CEEs were maintained in an automated egg incubator with a constant temperature of $37.5^{\circ} \mathrm{C}$ to $38^{\circ} \mathrm{C}$ and humidity of $40-55 \%$ for 5 days. The protocol of virus isolation was carried out according to the protocol described by Nunez et al. for CAstV and Nunez et al. for ANV $(27,35)$.

\section{Confirmation of Virus Isolation}

At 5 days post infection, the growth of the virus was examined by necropsy after chilling the embryos at $4^{\circ} \mathrm{C}$ for $1 \mathrm{~h}$. Pathological changes of the embryos, such as dwarfism, edema, gelatinous lesions, or hemorrhage, were observed. The confirmation of virus isolation was also confirmed by rRT-PCR.

\section{Sequencing and Molecular Analysis}

Two embryos of both virus isolates confirmed by rRT-PCR were macerated, and a 1:1 suspension with PBS was made. Next, the suspensions were homogenized and centrifuged in a refrigerated centrifuge machine for $30 \mathrm{~min}$ at $12,000 \times \mathrm{g}$. The supernatant was filtered with a $0.22 \mu \mathrm{M}$ filter. Next, $300 \mu \mathrm{l}$ of supernatant fluid containing cultured virus was socked in an FTA card
(Merck ${ }^{\circledR}$, Germany; maximum capacity is $500 \mu \mathrm{l}$ ) and sent for commercial Sanger sequencing. RNA was extracted from the FTA card punches, and cDNA was prepared by commercial kits and their protocols (RevertAid First Strand cDNA Synthesis Kit, Thermo Scientific). PCR was performed on both viruses with the primers and protocols described by Day et al. (36). The amplified products were purified (using ExoSAP-IT ${ }^{\mathrm{TM}}$, Applied Biosystems) and Sanger sequenced with a BigDye terminator v3.1 sequencing kit and a 3730xl automated sequencer (Applied Biosystems). The partial sequences of ORF1b were identified by a basic local alignment search tool (BLAST) search and compared with the published CAstV and ANV sequences deposited in the GenBank database. Next, the sequences were aligned and analyzed with other related sequences present in the GenBank database. The phylogenetic tree of both viruses was constructed using the software package MEGA X (37).

\section{Economic Parameter}

Based on the tested positive broiler flocks, the mortality rate was recorded over the last 7 days starting from the day of sample collection. The feed conversion rate (FCR\%) was calculated for only broilers over 30-35 days to sale or culling. The history of hatchability and egg production records of the corresponding flocks (broiler breeder, layer breeder and layer flock) to the onset of clinical examination were collected. The hatch drop and egg production drop were calculated from the difference between the onset and before the clinical examination.

\section{Statistics}

All collected raw data were entered into a Microsoft Excel 2010 (MS Excel) spreadsheet. Next, the correlation among the variables' estimated parameters was calculated using Pearson's 
TABLE 3 | Identification of CAstV and ANV in chickens in selected areas of Bangladesh (total flock $=31$ ).

\begin{tabular}{|c|c|c|c|c|c|c|c|c|c|c|}
\hline \multirow[t]{2}{*}{ Flock } & \multirow[t]{2}{*}{ Location } & \multirow[t]{2}{*}{ Age } & \multirow{2}{*}{$\begin{array}{l}\text { Type of } \\
\text { chicken }\end{array}$} & \multirow{2}{*}{$\begin{array}{c}\text { Flock } \\
\text { Mortality }^{a} \\
\text { (\%) }\end{array}$} & \multirow[t]{2}{*}{ FCR \% } & \multirow{2}{*}{$\begin{array}{c}\text { Hatch drop } \\
\%\end{array}$} & \multirow{2}{*}{$\begin{array}{l}\text { Egg } \\
\text { production } \\
\text { drop } \%\end{array}$} & \multicolumn{3}{|c|}{ rRT-PCR results } \\
\hline & & & & & & & & CAstV & ANV & Comments \\
\hline F10 & Gazipur & $29 W$ & Broiler breeder & 0 & - & $5.2^{*}$ & $12.23^{*}$ & Neg & Neg & - \\
\hline F11 & Gazipur & $27 \mathrm{~W}$ & Broiler breeder & 0 & - & $7.06^{\star}$ & $9.83^{*}$ & Neg & Neg & - \\
\hline F12 & Gazipur & $45 \mathrm{~W}$ & Broiler breeder & 0 & - & $5.42^{\star}$ & $16.51^{*}$ & Neg & Neg & - \\
\hline F13 & Gazipur & $41 \mathrm{~W}$ & Broiler breeder & 0 & - & $3.22^{\star}$ & $8.64^{\star}$ & Neg & Neg & - \\
\hline F14 & Gazipur & $30 W$ & Broiler breeder & 0 & - & $7.21^{\star}$ & $8.41^{\star}$ & Neg & Neg & - \\
\hline F15 & Gazipur & $30 W$ & Broiler breeder & 2.85 & - & $23.67^{\star \star}$ & $39.4^{\star \star}$ & Pos & Pos & CAstV, ANV \\
\hline F17 & Gazipur & $25 W$ & Broiler breeder & 3.11 & - & $18.16^{\star \star}$ & $22.62^{\star \star}$ & Pos & Neg & CAstV \\
\hline F18 & Gazipur & $46 W$ & Layer breeder & 2.04 & - & $15.33^{\star \star}$ & $24.81^{\star \star}$ & Pos & Neg & CAstV \\
\hline F19 & Gazipur & $42 W$ & Broiler breeder & 3.85 & - & $17.06^{\star \star}$ & $20.39^{\star \star}$ & Pos & Neg & CAstV \\
\hline F2O & Gazipur & $32 \mathrm{~W}$ & Broiler breeder & 2.77 & - & $20.52^{\star \star}$ & $26.3^{\star \star}$ & Pos & Neg & CAstV \\
\hline $\mathrm{F} 1$ & Mymensingh & $24 \mathrm{D}$ & Broiler & 7.29 & 1.83 & - & - & Pos & Pos & CAstV, ANV \\
\hline F2 & Gazipur & 25 D & Broiler & 6.89 & 2.23 & - & - & Neg & Pos & ANV \\
\hline F3 & Bogura & $25 \mathrm{D}$ & Broiler & 3.44 & 1.55 & - & - & Neg & Neg & - \\
\hline F4 & Mymensingh & $21 \mathrm{D}$ & Broiler & 5.61 & 1.9 & - & - & Pos & Pos & CAstV, ANV \\
\hline F5 & Bogura & $25 \mathrm{D}$ & Broiler & 7.89 & 2.06 & - & - & Pos & Neg & CAstV \\
\hline F6 & Gazipur & $28 \mathrm{D}$ & Broiler & 4.01 & 1.62 & - & - & Neg & Neg & - \\
\hline F7 & Mymensingh & $23 \mathrm{D}$ & Broiler & 3.23 & 1.68 & - & - & Neg & $\mathrm{Neg}$ & - \\
\hline F8 & Gazipur & $21 \mathrm{D}$ & Broiler & 4.07 & 1.8 & - & - & Neg & Neg & - \\
\hline F9 & Gazipur & 29 D & Broiler & 2.33 & 1.48 & - & - & Neg & Neg & - \\
\hline F16 & Rangpur & $16 \mathrm{D}$ & Broiler & 1.5 & 1.92 & - & - & Pos & Neg & CAstV \\
\hline F21 & Gazipur & 13 D & Broiler & 5.08 & 2.17 & - & - & Pos & Pos & CAstV, ANV \\
\hline F24 & Rangpur & $24 \mathrm{D}$ & Broiler & 4.17 & 1.9 & - & - & Pos & Pos & CAstV, ANV \\
\hline F25 & Rangpur & $24 \mathrm{D}$ & Broiler & 4.06 & 1.85 & - & - & Pos & Pos & CAstV, ANV \\
\hline F27 & Bogura & $23 \mathrm{D}$ & Broiler & 4.44 & 1.77 & - & - & Neg & Neg & - \\
\hline F28 & Bogura & $25 \mathrm{D}$ & Broiler & 3.93 & 1.79 & - & - & Neg & Neg & - \\
\hline F29 & Bogura & $29 \mathrm{D}$ & Broiler & 4.08 & 1.6 & - & - & Neg & Neg & - \\
\hline F30 & Bogura & $28 \mathrm{D}$ & Broiler & 2.87 & 1.82 & - & - & Neg & Neg & - \\
\hline F31 & Bogura & $21 \mathrm{D}$ & Broiler & 4.6 & 1.85 & - & - & Neg & Neg & - \\
\hline F22 & Gazipur & $22 W$ & Layer & 2.46 & - & $10.21^{\star \star}$ & $27.31^{\star \star}$ & Pos & Neg & CAstV \\
\hline F26 & Mymensingh & $11 \mathrm{~W}$ & Layer & 3.74 & - & - & - & Neg & Neg & - \\
\hline F23 & Gazipur & $13 \mathrm{D}$ & Indigenous & 1.72 & - & - & - & Pos & Neg & CAstV \\
\hline
\end{tabular}

* Significant at the 0.05 level; ${ }^{*}$ Significant at the 0.01 level. CAstV, Chicken astrovirus; ANV, Avian nephritis virus.

${ }^{a}$ The mortalities were recorded for 7 days from sampling day.

correlation method in SPSS (Statistical Package for the Social Sciences) software version 20 for statistical computing.

\section{RESULTS}

\section{Prevalence of CAstV and ANV}

Thirty-one cases were suspected to be RSS by both standard clinical signs and postmortem lesions in five types of chickens from four districts of Bangladesh during 2018. Overall, 15/31 (48.38\%) of examined cases were positive for Avastrovirus. Thus, 8/31 flocks (25.8\%) were positive for CAstV, 6/31 flocks (19.3\%) had mixed infection of CAstV and ANV, and 1 flock (3.2\%) was positive for ANV (Table 3). CAstV was positive in all examined 4 types of chickens: $38.88 \%$ (7/18) in broilers, $44.44 \%$ (4/9) in broiler breeders, $50 \%(1 / 2)$ in layers, $100 \%(1 / 1)$ in layer breeders, and $100 \%(1 / 1)$ in indigenous breeders (Table 4$)$. In the case of ANV, 33.33\% (6/18) of positive cases were observed in broiler and $11.11 \%(1 / 9)$ broiler breeder flocks, and no positive cases were observed in the remaining three types. Out of the 15 positive cases, a mixed infection with $\mathrm{CAst} V$ and $\mathrm{ANV}$ was found in only broiler and broiler breeder flocks in $5(5 / 15 ; 33.33 \%)$ and $1(1 / 15$; $6.66 \%$ ) cases, respectively (Table 4). According to the location of the outbreak, comparatively, the highest number of positive cases of both single and mixed infections of CAstV and ANV were found in the Gazipur district: 8 flocks tested positive for CAstV (8/17; 47.05\%), 3 flocks tested positive for ANV (3/17; $17.65 \%)$ and 2 flocks tested positive $(2 / 17 ; 11.76 \%)$ for mixed infection. For ANV, positive cases were found in $2(2 / 3 ; 66.66 \%)$ 
TABLE 4 | Identification of CAstV and ANV in types of chickens.

\begin{tabular}{lccc}
\hline Type of Chicken & \multicolumn{3}{c}{ rRT-PCR results } \\
\cline { 2 - 4 } & CAstV & ANV & CAstV+ANV \\
\hline Broiler $(n=18)$ & $2(11.11 \%)$ & - & $5(27.77 \%)$ \\
Broiler breeder $(n=9)$ & $3(33.33 \%)$ & $1(11.11 \%)$ & $1(11.11 \%)$ \\
Layer $(n=2)$ & $1(50 \%)$ & - & - \\
Layer breeder $(n=1)$ & $1(100 \%)$ & - & - \\
Indigenous $(n=1)$ & $1(100 \%)$ & - & $0.11^{*}$ \\
P & $0.015 *$ & $0.000^{\star *}$ & $6(19.35 \%)$ \\
\hline Total & $8(25.81 \%)$ & $1(3.22 \%)$ & - \\
\hline
\end{tabular}

*Significant at the 0.05 level; ${ }^{* *}$ Significant at the 0.01 level.

CAstV, Chicken astrovirus; ANV, Avian nephritis virus.

TABLE 5 | Identification of CAstV and ANV on location of chicken flocks.

\begin{tabular}{lccc}
\hline Location & \multicolumn{3}{c}{ rRT-PCR results } \\
\cline { 2 - 4 } & CAstV & ANV & CAstV+ANV \\
\hline Gazipur $(n=17)$ & $6(35.29 \%)$ & $1(5.88 \%)$ & $2(11.76 \%)$ \\
Rangpur $(n=3)$ & $1(33.33 \%)$ & - & $2(66.66 \%)$ \\
Mymensingh $(n=4)$ & - & - & $2(50.00 \%)$ \\
Bogura $(n=7)$ & $1(14.28 \%)$ & - & - \\
P & $0.013^{\star *}$ & $0.001^{\star *}$ & $0.034^{\star}$ \\
\hline Total & $8(25.81 \%)$ & $1(3.22 \%)$ & $6(19.35 \%)$ \\
\hline
\end{tabular}

*Significant at the 0.05 level; ${ }^{\star *}$ Significant at the 0.01 level.

CAstV, Chicken astrovirus; ANV, Avian nephritis virus.

of the Rangpur districts and $2(2 / 4 ; 50 \%)$ of the Mymensingh districts, but no cases were identified in the Bogura district. In addition, mixed infection cases were not found in poultry flocks in the Bogura district (Table 5). No Avian reovirus coinfection was identified in the tested samples.

\section{Isolation of CAstV and ANV}

In this study, only two isolates from both viruses were cultured in SPF CEE because of the unavailability of SPF chicken eggs. Here, both the CAstV and ANV of each of the two isolates were shown to have growth in lesions observed after one passage that continued to the second passage (Figure 2). Next, the virus isolates were confirmed using the rRT-PCR test. No pathological lesions on embryos were observed in the negative controls for either virus.

\section{Sequencing of CAstV and ANV}

The obtained partial nucleotide sequence of the ORF1b gene of four isolates (two of each virus) was submitted to the NCBI GenBank under accession numbers MK929649.1 (CAstV/ BLRI/BD/2018/1), MK929650.1 (CAstV/BLRI/BD/2018/2), MK975886.1 (ANV/BLRI/BD/2018/3), and MK975885.1 (ANV/BLRI/BD/2018/4). The Basic Local Alignment Search Tool (BLAST) search revealed that 2 CAstV sequences of Bangladesh origin were similar to the $\mathrm{CAstV}$ sequences of

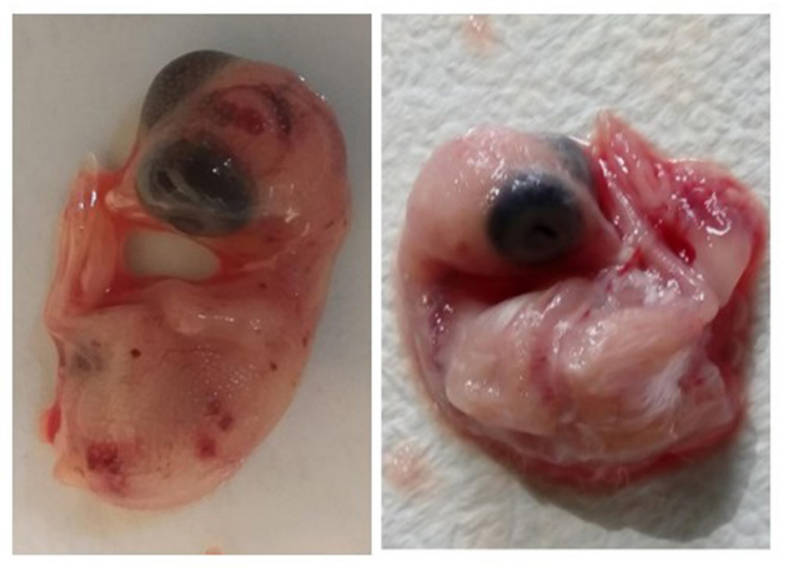

FIGURE 2 | The hemorrhagic, edematous chicken embryos with gelatinous lesions and dwarfism due to growth of virus after inoculation of virus through yolk sac route (left image) and non-infected chicken embryo (right image).

Brazil (MK929649.1 is 99.45\% with Brazilian KR013276.1) and India (MK929650.1 is $99.18 \%$ with Indian KT386328.1). Another two sequences of ANV of Bangladesh origin were closely related to an ANV-1 strain and similar to an ANV sequence from India (MK975886.1 and MK975885.1 are 98.90\% similar to KT376415.1 and KT376413.1, respectively). Notably, the in-between sequences of CAstV and ANV are identical. The relationships among the sequences were described by a phylogenetic tree (Figure 3).

\section{Economic Impact of CAstV and ANV}

Broiler flocks recorded significantly lower FCR\%, and a higher mortality rate was observed in the flocks infected with both $\mathrm{CAstV}$ and $\mathrm{ANV}$ compared with infection with a single virus. The lowest flock mortality $(1.50 \%)$ was in flock number F16, which had a better FCR\% (1.83\%) than being infected by only CAstV (Table 3). A significant correlation was observed among flock mortality (\%), FCR\%, and infection with CAstV and ANV for the selected flocks. The hatch drop and egg production drop were found to be significantly higher in flocks infected with CAstV and ANV.

\section{DISCUSSION}

The cause of RSS in poultry is multifactorial (3, 32, 38). RSS symptoms are observed regularly by poultry veterinarians in Bangladesh, but no investigations have been carried out to determine the role of $\mathrm{CAstV}$ or $\mathrm{ANV}$ as viral agents in this syndrome.

Many virologic confirmations have been established to diagnose CAstV and ANV, such as isolation by cell culture or embryo inoculation, but this process is complicated and timeconsuming for screening an entire flock, and using specific antisera for identification of a virus is also complicated (39, 40). However, rRT-PCR and conventional RT-PCR are highly 


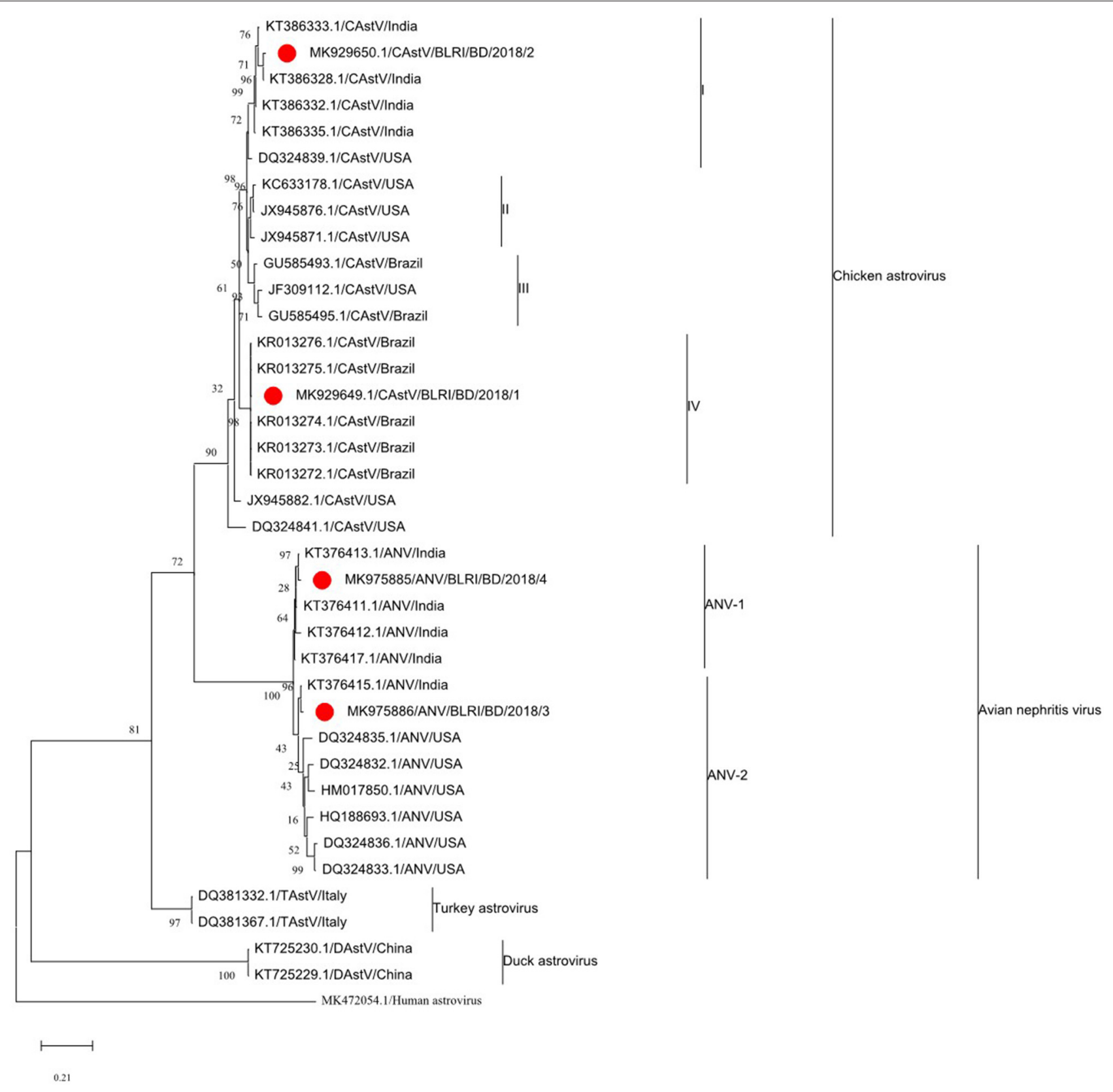

FIGURE 3 | The phylogenetic tree was constructed using MEGA X software on the alignments of the partial ORF1b sequences of CAstV (362 nucleotide length)and ANV (473 nucleotide length) using a neighbor-joining phylogeny method joined with the maximum composite likelihood model with 1,000 bootstraps of replication. The tree showed the phylogenetic relationships of the Bangladeshi CAstV and ANV isolates in SPF CEEs with other sequences present in GenBank. The numbers along the branches show the bootstrap value for every 1,000 replicates. The scale bar represents the number of substitutions per site. The GenBank accession numbers and host species of the sequences used here are shown in the tree. The red color with bold sequences is Bangladeshi isolates. The human astrovirus 1 sequence was used as an outgroup.

sensitive and specific as well as rapid and compatible for screening and diagnosis of clinical samples (22, 26, 27, 39-41).

In this investigation, real-time RT-PCR was used to detect viral RNA of both CAstV and ANV in pooled samples of liver, kidney, and intestine (duodenum, cecum) from clinically suspected poultry flocks. Many researchers have identified both $\mathrm{CAstV}$ and $\mathrm{ANV}$ in a wide range of samples, such as liver, kidney, cecum, duodenum, intestinal contents, and yolk, and found a comparatively higher concentration of ANV RNA in intestinal or gut samples $(10,11,27,32,39-42)$.

This study confirmed that $48.38 \%$ (15/31) of flocks were positive for CAstV and ANV either as a single infection or mixed infection in broilers, broiler breeders, layers, layer breeders, and indigenous chickens in different districts in Bangladesh. The 
results indicate that broiler flock mortality rates were increased in flocks with a mixed infection compared with flocks with a single infection. Similar observations in South Korea were published by Koo et al., who surveyed South Korean poultry farms with enteric disorders and reported that seven enteric viruses with three bacterial coinfections were involved (26). They demonstrated that the flocks had higher rates of infection with ANV (44.1\%) than with CAstV (38.2\%), and $51.7 \%$ of cases were infected with at least two or more enteric viruses. In contrast, Oluwayelu et al. reported a higher prevalence compared with our experience, namely, $92.3 \%$ of ANV and $53.9 \%$ of $\mathrm{CAstV}$ in Nigerian indigenous chickens (42). Another survey was conducted in the United States that isolated CAstV from $90 \%$ healthy as subclinical infection and 100\% from an RSSreported chicken flock when intestinal contents were tested by rRT-PCR (4).

Mixed infection with multiple enteric viruses and bacteria has been demonstrated to have a more severe effect and prolonged enteritis than infection with a single virus in poultry $(4,26)$. Therefore, multiple infections increase flock mortality rates and decrease the FCR to a greater extent in broiler-type chickens (6). They are also risk factors for secondary infections with opportunistic pathogens such as Escherichia coli, Salmonella spp., and Eimeria spp., which disrupt the normal physiology of the enteric mucosa. Thus, impaired nutrition absorption and impaired development of primary defense organs such as the thymus and bursa of Fabricius results in chicks suffering from different malabsorption syndromes, such as RSS $(2,26)$. CAstV infection in broiler breeder flocks significantly decreased egg production up to $21 \%$ and decreased hatchability rates up to $68.4 \%$ (43). Broilers are the most susceptible to CAstV and ANV, resulting in an increased mortality of up to $40 \%$ in their first week of age and interstitial nephritis and gout (12). Chickens in the first 3 weeks of life are more susceptible to simultaneous infection with enteric viruses $\mathrm{CAstV}, \operatorname{ANV}$, and $\operatorname{ARV}(22,26)$. We could not confirm articular gout is mainly by CAstVs or not but that was our findings on most of chickens that confirmed CAstVs cases and we suggested further studies on correlation between CAstVs and articular gout.

In this study, four types of commercial poultry production and one indigenous chicken flock were infected with CAstV where most of the broiler chickens infected with combined of CAstV and ANV. This indicates that these viruses are widely circulating and are probably endemic throughout the country, which should be alarming to the poultry industry. The actual prevalence of this virus in Bangladeshi poultry industries may be higher than that in this study, since the extent of spread of avian enteric viruses remains unclear.

CAstV and ANV can grow well in the CEE through the yolk sac route. Inoculation of a virus through the yolk sac route in 7-day-old embryonated eggs is the standard method for virus isolation (22). In contrast, in this study, 14-day-old embryonated eggs were inoculated because of the enteric nature of CAstV and ANV and because the intestine would already be developed and functional at this stage of embryo development, which may improve virus isolation (44).

Genetically, the sequence of the ORF1b conserved region of $\mathrm{CAst} \mathrm{V}$ and $\mathrm{ANV}$ confirmed that the viruses were the causal agents of RSS and circulated in chickens. Analysis of the nucleic acid sequences of this study revealed their similarity with reported viruses from India and other parts of the world (45). All CAstV and ANV of this study were clustered in a group of ORF1b polymerase gene phylogeny. Kaithal et al. (46) analyzed the ORF1b genes of CAstV and ANV and revealed that Indian isolates of CAstV and ANV were aligned with circulating and Brazilian sequences of the respective viruses. It could be assumed that transboundary transmission of both viruses through neighboring borders may occur. Further ORF2 sequence analysis is recommended to investigate the antigenic variation of our isolates. Cloning and whole genome sequencing of $\mathrm{CAstV}$ and $\mathrm{ANV}$ is essential to extend genetic diversity and to discover genetic variations in diverse poultry species (45). Consequently, differential diagnosis in a poultry flock with decreased FCR, enteritis, poor hatchability, and retarded growth should consider RSS caused by CAstV and ANV.

CAstV and ANV infection directly impact egg production drops and hatchability drops in broiler breeder flocks. Hatchability losses are prominent during mid-period and late-period incubation, and they can be caused by the chicks being too weak to hatch out or slow to hatch $(17,47,48)$. In this study, a significant correlation was found between egg production drop and hatchability drop with flocks positive for CAstV and ANV.

\section{CONCLUSION}

This is the first report of molecular evidence of chicken astrovirus (CAstV) and avian nephritis virus (ANV) in chickens with runting-stunting syndrome in Bangladesh. The sequencing results confirmed that the identified CAstV in Bangladesh is similar to strains isolated from Brazil and India. The $\mathrm{ANV}$ is grouped with ANV-1 and is closely related to strains isolated from India. Our results will be useful for diagnosis and vaccine development for both CAstV and ANV in Bangladesh. More extensive epidemiological studies, whole genome sequencing and pathogenicity studies of circulating strains are recommended.

\section{DATA AVAILABILITY STATEMENT}

The raw data supporting the conclusions of this article will be made available by the authors, without undue reservation.

\section{ETHICS STATEMENT}

The animal study was reviewed and approved by The Animal Experimentation Ethics Committee approval number: BLRI0005.

\section{AUTHOR CONTRIBUTIONS}

HJS and MZA supervised this project, designed the experiments, and prepared manuscript. MMM, ZAB, and MG collected 
samples and performed experiments. All authors read and approved the final manuscript.

\section{FUNDING}

This work was supported by the Chungnam National University, South Korea.

\section{REFERENCES}

1. Hafez HM. Enteric diseases of poultry with special attention to Clostridium perfringens. Pakm Vet J. (2011) 31:175-84.

2. Guy JS. Virus infections of the gastrointestinal tract of poultry. Poult Sci. (1998) 77:1166-75. doi: 10.1093/ps/77.8.1166

3. Palade EA, Kisary J, Benyeda Z, Mándoki M, Balka G, Jakab C, et al. Naturally occurring parvoviral infection in Hungarian broiler flocks. Avian Pathol. (2011) 40:191-7. doi: 10.1080/03079457.2011.553213

4. Pantin-Jackwood MJ, Spackman E, Woolcock PR. Molecular characterization and typing of chicken and turkey astroviruses circulating in the United States: implications for diagnostics. Avian Dis. (2006) 50:397-404. doi: 10.1637/7512-020606R.1

5. Otto PH, Ahmed MU, Hotzel H, Machnowska P, Reetz J, Roth B, et al. Detection of avian rotaviruses of groups A, D, F and G in diseased chickens and turkeys from Europe and Bangladesh. Vet Microbiol. (2012) 156:815. doi: 10.1016/j.vetmic.2011.10.001

6. Ali MZ, Moula MM, Bhuiyan ZA, Javed MT. A cross sectional survey of chicken astroviruses antibody in broiler and Sonali (cross-bred) chickens in selected areas in Bangladesh. Maced Vet Rev. (2020) 43:7580. doi: 10.2478/macvetrev-2020-0016

7. Nunez LF, Parra SH, Mettifogo E, Catroxo MH, Astolfi-Ferreira CS, Ferreira AJ. Isolation of chicken astrovirus from specific pathogen-free chicken embryonated eggs. Poult Sci. (2015) 94:947-54. doi: 10.3382/ps/pev086

8. Sajewicz-Krukowska J, Pać K, Lisowska A, Pikuła A, Minta Z, Króliczewska $\mathrm{B}$, et al. Astrovirus-induced "white chicks" condition-field observation, virus detection and preliminary characterization. Avian Pathol. (2016) 45:212. doi: 10.1080/03079457.2015.1114173

9. Yuan X, Meng K, Zhang Y, Yu Z, Ai W, Wang Y. Genome analysis of newly emerging goose-origin nephrotic astrovirus in China reveals it belongs to a novel genetically distinct astrovirus. Infect Genet Evol. (2019) 67:16. doi: 10.1016/j.meegid.2018.10.014

10. Smyth VJ, Jewhurst HL, Adai BM, Todd D. Detection of chicken astrovirus by reverse transcriptase-polymerase chain reaction. Avian Pathol. (2009) 38:293-9. doi: 10.1080/03079450903055397

11. Day JM, Oakley BB, Seal BS, Zsak L. Comparative analysis of the intestinal bacterial and RNA viral communities from sentinel birds placed on selected broiler chicken farms. PLoS ONE. (2015) 10:e0117210. doi: 10.1371/journal.pone.0117210

12. Bulbule NR, Mandakhalikar KD, Kapgate SS, Deshmukh VV, Schat KA, Chawak MM. Role of chicken astrovirus as a causative agent of gout in commercial broilers in India. Avian Pathol. (2013) 42:46473. doi: 10.1080/03079457.2013.828194

13. Day JM, Zsak L. Recent progress in the characterization of avian enteric viruses. Avian Dis. (2013) 57:573-80. doi: 10.1637/10390-092712-Review.1

14. Goodwin MA, Davis JF, McNulty MS, Brown J, Player EC. Enteritis (socalled runting stunting syndrome) in Georgia broiler chicks. Avian Dis. (1993) 37:451-8. doi: 10.2307/1591672

15. Kang KI, Linnemann E, Icard AH, Durairaj V, Mundt E, Sellers HS. Chicken astrovirus as an aetiological agent of runting-stunting syndrome in broiler chickens. J Gen Virol. (2018) 99:512-24. doi: 10.1099/jgv.0.001025

16. Kang KI, El-Gazzar M, Sellers HS, Dorea F, Williams SM, Kim T, et al. Investigation into the aetiology of runting and stunting syndrome in chickens. Avian Pathol. (2012) 41:41-50. doi: 10.1080/03079457.2011.632402

17. Smyth VJ, Jewhurst HL, Wilkinson DS, Adair BM, Gordon AW, Todd D. Development and evaluation of real-time TaqMan $®$ RT-PCR assays for the

\section{ACKNOWLEDGMENTS}

We acknowledge the cordial support of all laboratory staff, poultry farm owners, and flock workers to complete the research. We also kindly acknowledge the Department of Research and Development, Nourish Poultry and Hatchery, Ltd. for their financial support. This work was also supported financially by a grant from Chungnam National University.

detection of avian nephritis virus and chicken astrovirus in chickens. Avian Pathol. (2010) 39:467-74. doi: 10.1080/03079457.2010.516387

18. Pantin-Jackwood M, Todd D, Koci MD. Avian Astroviruses. In: Virus taxonomy: classification and nomenclature of viruses (Ninth Report of the International Committee on the Taxonomy of Viruses). King AMQ, Lefkowitz E, Adams MJ, Carstens EB, editors. New York: Elsevier Academic Press. (2011). pp. 151-180. doi: 10.1007/978-1-4614-4735-1_9

19. Bosch A, Guix S, Krishna NK, Mendez E, Monroe SS, Pantin-Jackwood M, et al. Family Astroviridae. In: Virus taxonomy: classification and nomenclature of viruses (Ninth Report of the International Committee on the Taxonomy of Viruses). King AMQ, Lefkowitz E, Adams MJ, Carstens EB, editors. New York: Elsevier Academic Press. (2011). pp. 953-959.

20. Guix S, Bosch A, Pinto' R. Astrovirus Taxonomy. In: Schultz-Cherry S, editors. Astrovi'rus research: essential ideas, everyday impacts, future directions. New York: Springer Science+Business Media. (2013). pp 65-78.

21. Espinoza LL, Beserra LAR, Soares RM, Gregori F. Avian nephritis virus (ANV) on Brazilian chickens farms: circulating genotypes and intra-genotypic diversity. Arch Virol. (2016) 161:3455-62. doi: 10.1007/s00705-016-3057-7

22. Reynolds DL, Saif YM, Theil KW. Enteric viral infections of turkey poults: incidence of infection. Avian Dis. (1987) 31:272-6. doi: 10.2307/1590872

23. Baxendale $\mathrm{W}$, Mebatsion $\mathrm{T}$. The isolation and characterisation of astroviruses from chickens. Avian Pathol. (2004) 33:36470. doi: 10.1080/0307945042000220426

24. Mendenhall IH, Yaung KN, Joyner PH, Keatts L, Borthwick S, Neves ES, et al. Detection of a novel astrovirus from a black-naped monarch (Hypothymis azurea) in Cambodia. Virol J. (2015) 12:1-5. doi: 10.1186/s12985-015-0413-2

25. De la Torre DI, Nuñez LF, Astolfi-Ferreira CS, Piantino Ferreira AJ. Enteric virus diversity examined by molecular methods in Brazilian poultry flocks. Vet Sci. (2018) 5:38. doi: 10.3390/vetsci5020038

26. Koo BS, Lee HR, Jeon EO, Han MS, Min KC, Lee SB, et al. Molecular survey of enteric viruses in commercial chicken farms in Korea with a history of enteritis. Poult Sci. (2013) 92:2876-85. doi: 10.3382/ps.2013-0 3280

27. Nuñez LF, Parra SH. De la Torre D, Catroxo MH, Buim MR, Chacon RV, et al. Isolation of avian nephritis virus from chickens showing enteric disorders. Poult Sci. (2018) 97:3478-88. doi: 10.3382/ps/pey207

28. Yamaguchi S, Imada T, Kawamura H. Characterization of a picornavirus isolated from broiler chicks. Avian Dis. (1979) 571-81. doi: 10.2307/1589732

29. Imada $\mathrm{T}$, Yamaguchi S, Mase $M$, Tsukamoto $\mathrm{K}$, Kubo M, Morooka A. Avian nephritis virus (ANV) as a new member of the family Astroviridae and construction of infectious ANV cDNA. J Virol. (2000) 74:848793. doi: 10.1128/JVI.74.18.8487-8493.2000

30. Castro CM, Chagas EH, Bezerra DA, da Silva SP, Cruz AC, Sousa Júnior EC, et al. First whole-genome characterization of avian nephritis virus 2 of broiler chicken from Pará, Brazil. Genome Announc. (2018) 6:0051018. doi: 10.1128/genomeA.00510-18

31. Gowthaman V, Singh SD, Dhama K, Barathidasan R, Srinivasan P, Saravanan $S$, et al. Detection and partial genetic characterisation of a novel variant of Avian nephritis virus in Indian poultry flocks showing diverse clinical signs. Acta Vet Hung. (2015) 3:499-507. doi: 10.1556/004.2015.046

32. Hewson KA, O'Rourke D, Noormohammadi AH. Detection of avian nephritis virus in Australian chicken flocks. Avian Dis. (2010) 54:9903. doi: 10.1637/9230-010610-Reg.1

33. Xue J, Han T, Xu M, Zhao J, Zhang G. The first serological investigation of Chicken astrovirus infection in China. Biologicals. (2017) 47:224. doi: 10.1016/j.biologicals.2017.03.005 
34. Pantin-Jackwood MJ, Day JM, Jackwood MW, Spackman E. Enteric viruses detected by molecular methods in commercial chicken and turkey flocks in the United States between 2005 and 2006. Avian Dis. (2008) 52:23544. doi: 10.1637/8174-111507-Reg.1

35. Nuñez LFN, Parra SS, Carranza C, Astolfi-Ferreira CS, Buim MR, Ferreira AP. Detection and molecular characterization of chicken astrovirus associated with chicks that have an unusual condition known as "white chicks" in Brazil. Poult Sci. (2016) 95:1262-70. doi: 10.3382/ps/pew062

36. Day JM, Spackman E, Pantin-Jackwood M, A. multiplex RT-PCR test for the differential identification of turkey astrovirus type 1, turkey astrovirus type 2, chicken astrovirus, avian nephritis virus, and avian rotavirus. Avian Dis. (2007) 51:681-4. doi: 10.1637/1933-5334(2007)2[e13:AMRTFT]2.0.CO;2

37. Kumar S, Stecher G, Li M, Knyaz C, Tamura K, MEGA X. molecular evolutionary genetics analysis across computing platforms. Mol Biol Evol. (2018) 35:1547-9. doi: 10.1093/molbev/msy096

38. Canelli E, Cordioli P, Barbieri I, Catella A, Pennelli D, Ceruti R, et al. Astroviruses as causative agents of poultry enteritis: genetic characterization and longitudinal studies on field conditions. Avian Dis. (2012) 56:17382. doi: 10.1637/9831-061311-Reg.1

39. Mándoki M, Dobos-Kovacs M, Bakonyi T, Rusvai M. Molecular diagnosis of avian nephritis: preliminary report. Acta Vet Hung. (2006) 54:5160. doi: 10.1556/avet.54.2006.1.6

40. Michael DJ, Spackman E, Pantin-Jackwood M, A. multiplex RT-PCR test for the differential identification of turkey astrovirus type 1, turkey astrovirus type 2, chicken astrovirus, avian nephritis virus, and avian rotavirus. Avian Dis. (2007) 51:681-4. doi: 10.1637/0005-2086(2007)51[681:AMRTFT]2.0.CO;2

41. Todd D, Trudgett J, McNeilly F, McBride N, Donnelly B, Smyth VJ, et al. Development and application of an RT-PCR test for detecting avian nephritis virus. Avian Pathol. (2010) 39:207-13. doi: 10.1080/030794510037 67253

42. Oluwayelu DO, Smyth V, Todd D. Detection of avian nephritis virus and chicken astrovirus in Nigerian indigenous chickens. African J Biotechnol. (2012) 11:3949-57. doi: 10.5897/AJB11.1655

43. Nuñez LFN, Piantino FAJ. Viral agents related to enteric disease in commercial chicken flocks, with special reference to Latin America. Worlds Poult Sci J. (2013) 69:853-64. doi: 10.1017/S00439339130 00858
44. Karcher DM, Applegate T. Survey of enterocyte morphology and tight junction formation in the small intestine of avian embryos. Poult Sci. (2008) 87:339-50. doi: 10.3382/ps.2007-00342

45. Patel AK, Pandit RJ, Thakkar JR, Hinsu AT, Pandey VC, Pal JK, et al. Complete genome sequence analysis of chicken astrovirus isolate from India. Vet Res Comm. (2017) 41:67-75. doi: 10.1007/s11259-016-9673-6

46. Kaithal B, Jindal N, Kumar P, Mor SK. Detection and molecular characterization of enteric viruses in enteritis-affected commercial broiler chickens in India. Acta Virol. (2016) 60:361-71.doi: 10.4149/av_2016_04_361

47. Long KE, Ouckama RM, Weisz A, Brash ML, Ojkić D. White chick syndrome associated with chicken astrovirus in Ontario, Canada. Avian Dis. (2018) 62:247-58. doi: 10.1637/11802-012018-Case.1

48. Long KE, Hastie GM, Ojkić D, Brash ML. Economic impacts of white chick syndrome in Ontario, Canada. Avian Dis. (2017) 61:4028. doi: 10.1637/11592-012217-CaseR

Conflict of Interest: MMM and ZAB are employed by Nourish Central Poultry Laboratory, Nourish Poultry and Hatchery Ltd., Dhaka, Bangladesh.

The remaining authors declare that the research was conducted in the absence of any commercial or financial relationships that could be construed as a potential conflict of interest.

Publisher's Note: All claims expressed in this article are solely those of the authors and do not necessarily represent those of their affiliated organizations, or those of the publisher, the editors and the reviewers. Any product that may be evaluated in this article, or claim that may be made by its manufacturer, is not guaranteed or endorsed by the publisher.

Copyright (C) 2021 Ali, Moula, Bhuiyan, Giasuddin and Shin. This is an open-access article distributed under the terms of the Creative Commons Attribution License (CC $B Y)$. The use, distribution or reproduction in other forums is permitted, provided the original author(s) and the copyright owner(s) are credited and that the original publication in this journal is cited, in accordance with accepted academic practice. No use, distribution or reproduction is permitted which does not comply with these terms. 